\title{
Association of blood pressure in adolescence with birthweight
}

P O D Pharoah, C J Stevenson, C R West

\begin{abstract}
Aims-To compare the blood pressure of very low birthweight infants with that of normal birthweight controls in adolescence.
\end{abstract}

Methods-A cohort of all infants of birthweight $\leqslant 1500 \mathrm{~g}$ born to women resident in the county of Merseyside in 1980-1 was followed up at age 15 years with age, sex, and school matched controls. Growth indices and blood pressures were measured under standard conditions. The smoking history of mothers and children and their status for several socioeconomic variables were documented. In a matched pairs analysis systolic and diastolic blood pressures were compared for cases and controls before and after adjusting for height, weight, and body mass index.

Results-There were 172 singleton 15 year old survivors of birthweight $<1500 \mathrm{~g}$ out of 40321 live births to Merseyside residents in 1980-1. Of the 172 survivors, $128(74 \%)$ who had no clinical disability and $11(6 \%)$ with a clinical disability but attending normal schools, were assessed with individually matched age, sex, and school controls. Twenty three (13\%) had a clinical disability and were attending special schools; these were assessed without controls. Ten $(6 \%)$ children refused or were unavailable for assessment. The systolic blood pressure was significantly higher in cases than in controls; the mean of the difference was $3.2 \mathrm{~mm} \mathrm{Hg}$. The diastolic blood pressure was also higher in the cases, but the difference was not significant. The controls were significantly heavier $(4.4 \mathrm{~kg})$, taller $(4.0 \mathrm{~cm})$, with larger head circumference $(1.5 \mathrm{~cm})$ than the cases. The difference in body mass index was not significant. Adjusting for height, weight, or body mass index increased the difference in systolic blood pressure between cases and controls. There were no significant differences in the socioeconomic variables, but what differences did exist favoured the controls. There was also a higher prevalence of smoking among the children and the mothers of the cases than the controls.

Conclusions-The study supports the hypothesis that in adolescents variation in systolic blood pressure has its origins in fetal development. Some of the variation could be attributed to socioeconomic differences.

(Arch Dis Child Fetal Neonatal Ed 1998;79:F114-F118)
Keywords: blood pressure; adolescence; birthweight; socioeconomic circumstances

Ecological studies that reported a correlation between past infant mortality and current adult cardiovascular mortality ${ }^{12}$ led to the hypothesis that the intrauterine and infant environment had an important role in later mortality. Ecological studies, however, are subject to the ecological fallacy ${ }^{3}$ and the need for cohort studies to relate measures of fetal and infant development to specific risk factors for cardiovascular disease arose.

Several such studies have reported a negative association between birthweight and blood pressure in childhood ${ }^{4-8}$ and adulthood..$^{9-14}$ These have largely provided supportive evidence for the hypothesis that fetal and infant development programmes the individual and influences the development of risk factors for subsequent cardiovascular disease such as impaired glucose tolerance ${ }^{15}$ and hypertension. ${ }^{9}{ }^{12}{ }^{13}$ In contrast to children and adults, the association between birthweight and blood pressure in adolescents is inconsistent. ${ }^{16-20}$

We followed up of a geographically defined cohort of low birthweight infants and matched controls from birth. They were assessed when aged 15 years and the correlation between blood pressure and measures of fetal development examined.

\section{Methods}

A cohort comprising all infants of birthweight $\leqslant 1500 \mathrm{~g}$ born in 1980 and 1981, to mothers resident in the county of Merseyside, was obtained from birth notifications. The obstetric and neonatal records were abstracted for demographic and clinical details of the mother and the birthweight and head circumference of the child. Subsequently the infants were examined when aged 3 years to determine the prevalence of disability ${ }^{21}$ and again when aged 8 years to determine the prevalence of subclinical deficits of cognitive and motor function $^{22}$ and of behavioural disorders. ${ }^{23} \mathrm{At}$ the 8 year follow up, for those children attending normal school, an age and sex matched control from the same school was also assessed. The intention behind matching for schools was that, because primary schools tend to draw children from socially homogenous areas, it would effectively match for important social variables. This premise was tested at the 8 year follow up, when cases and controls were compared for several socioeconomic variables, including social class, current employment status of the father, housing status of the family, parental education and income and the 
number of children in the family. All these indices were marginally in favour of better social circumstances for the controls but none was significant. The only significant difference was that fewer cases than controls were living with both natural parents. ${ }^{23}$

The children were reassessed when aged 15 years with the same controls, when possible, as at the 8 year follow up. The children have now moved from primary to secondary schools and in some instances cases and controls were at different secondary schools. If the original control from primary school was not available, a new control of the same sex, in the same class at secondary school, and nearest in birth date to the index child was selected.

SURVEY MEASURES

All the assessments were carried out by one examiner (CJS) either at school or in the home. Blood pressure was measured in the left arm after the child had been seated for about 15 minutes during which time s/he completed a questionnaire. Three readings of the blood pressure were made at one minute intervals using a Dinamap 1846SX automated oscillometric monitor and a small adult size cuff. The last of the three readings was used in the analysis. The Dinamap was calibrated daily and serviced at 6 monthly intervals.

Height was measured using a portable stadiometer (the Leicester Height Measure), to the nearest $0.5 \mathrm{~cm}$, with the child standing on a firm level surface. Weight was measured to the nearest $0.5 \mathrm{~kg}$, with the child lightly clothed, using SECA Patient Scales. Body mass index was determined as weight $(\mathrm{kg}) /$ height (metres $)^{2}$. Head circumference was measured using a steel tape passing over the occipital protuberance.

A questionnaire to the mothers of cases and controls elicited information on their current smoking habit or whether they had ever smoked. For the control children only, the birthweight of the child was elicited by questionnaire. The birthweight of the index children had been extracted from the obstetric records when the cohort was initially established. The child's current smoking habit was obtained by a self-completed questionnaire.

STATISTICAL METHODS AND POWER

CALCULATIONS

Power calculations for the study were based on regional differences in the mean blood pressure of children reported from the Regional Heart Study. ${ }^{24}$ The range of mean systolic blood pressures in the regions was $96.7-102.4 \mathrm{~mm}$ with a standard deviation range of 8.6 to 8.7 $\mathrm{mm}$. The range of mean diastolic blood pressures was 55.9 to $60.1 \mathrm{~mm}$ and the standard deviation range was 5.9 to $6.0 \mathrm{~mm}$. Based on these data, the sample of children available for the study would allow, with an $80 \%$ power $(1-\beta=0.8)$ and $\alpha=0.05$, detection of a $3.5 \mathrm{~mm}$ difference in mean systolic, and a $2.5 \mathrm{~mm}$ difference in mean diastolic, pressure between cases and controls.

Statistical analysis was carried out using the Statistical Package for Social Sciences (SPSS).The paired Student $t$ test was used to determine if the mean of the differences between each case control pair differed from zero for the continuous variables. The unpaired Student $t$ test was used for continuous variables when comparing disabled and non-disabled children. McNemar's test for paired data was used to compare the current smoking of cases and controls and smoking during pregnancy of the mothers of cases and controls. Simple linear regression was used to adjust systolic and diastolic blood pressure for height, weight, and body mass index individually before a paired case control comparison.

\section{Results}

There were 40321 live births in Merseyside in 1980-1; 399 weighed $\leqslant 1500 \mathrm{~g}$ at birth, of whom 219 survived to age 15 years; $172(79 \%)$ of the survivors were singletons and comprise the results reported here. Of the 172 singletons, $128(74 \%)$ were children with no disability attending normal schools for each of whom there was an age, sex, and school matched control. Eleven $(6 \%)$ children with a disability but attending normal schools were also assessed, each with a matched control; 23 (13\%) children with a disability and attending special schools were assessed without matched controls and are reported as a separate group; 10 $(6 \%)$ children refused assessment, were untraced, or had moved abroad. Of the 219 survivors from the total cohort, 47 were from multiple pregnancies and were excluded from the analysis. This report is of 139 singleton (128 non-disabled +11 disabled at normal school) children with their matched controls and 23 disabled singleton children at special schools without controls.

The mean birthweight of the 128 nondisabled index cases was $1249 \mathrm{~g}$ (range 630 to $1500 \mathrm{~g}$ ) and for the controls was $3338 \mathrm{~g}$ (range 2098 to $4550 \mathrm{~g}$ ). The gestational age of the index cases ranged from 26 to 37 weeks with a mean of 30.7 weeks. Data on the gestational

Table 1 Comparisons of anthropometric indices in non-disabled and disabled singleton cases and their matched controls and disabled singleton cases attending special schools (who have no controls)

\begin{tabular}{|c|c|c|c|c|c|c|c|}
\hline $\begin{array}{l}\text { Anthropometric } \\
\text { measures }\end{array}$ & $\begin{array}{l}\text { Non-disabled } \\
\text { singleton cases } \\
(n=128)\end{array}$ & $\begin{array}{l}\text { Matched controls } \\
(n=128)\end{array}$ & $\begin{array}{l}\text { Mean of differences } \\
\text { between cases and } \\
\text { controls (95\% CI) }\end{array}$ & $\begin{array}{l}\text { Disabled } \\
\text { singleton cases } \\
(n=11)\end{array}$ & $\begin{array}{l}\text { Matched controls } \\
(n=11)\end{array}$ & $\begin{array}{l}\text { Mean of differences } \\
\text { between cases and controls } \\
(95 \% \text { CI) }\end{array}$ & $\begin{array}{l}\text { Disabled cases } \\
\text { with no controls } \\
(n=23)\end{array}$ \\
\hline Height $(\mathrm{cm})$ & 159.7 (SD 7.9) & 163.7 (SD 7.8) & $\begin{array}{l}-4.0(-2.1 \text { to }-5.9) \\
p<0.001\end{array}$ & $153.8($ SD 5.8) & $162.4(\mathrm{SD} 6.8)$ & $\begin{array}{l}-8.6(-2.3 \text { to }-14.9) \\
p<0.02\end{array}$ & 151.5 (SD 9.0) \\
\hline Weight (kg) & $50.8(\mathrm{SD} 10.7)$ & $55.3(\mathrm{SD} 10.5)$ & $\begin{array}{l}-4.4(-1.8 \text { to }-7.0) \\
\mathrm{p}=0.001\end{array}$ & 47.8 (SD 9.8) & $56.3(\mathrm{SD} 9.3)$ & $\begin{array}{l}-8.5(-0.8 \text { to }-16.2) \\
p<0.05\end{array}$ & 43.7 (SD 10.1) \\
\hline Body mass index & $19.8(\mathrm{SD} 3.3)$ & $20.6(\mathrm{SD} 3.2)$ & $\begin{array}{l}-0.7(-1.5 \text { to }+0.1) \\
0.1>p>0.05\end{array}$ & $20.3(\mathrm{SD} 4.5)$ & $21.2(\mathrm{SD} 2.6)$ & $\begin{array}{l}-1.0(-3.5 \text { to }+1.5) \\
\text { not significant }\end{array}$ & $19.0(\mathrm{SD} 4.0)$ \\
\hline $\begin{array}{l}\text { Head circumference } \\
\quad(\mathrm{cm})\end{array}$ & $55.1(\mathrm{SD} 1.9)$ & 56.7 (SD 1.6) & $\begin{array}{l}-1.5(-1.1 \text { to }-1.9) \\
\mathrm{p}<0.001\end{array}$ & $53.5(\mathrm{SD} 2.0)$ & $56.2(\mathrm{SD} 2.1)$ & $\begin{array}{l}-2.8(-0.9 \text { to }-4.7) \\
\mathrm{p}<0.01\end{array}$ & $53.9(\mathrm{SD} 1.6)$ \\
\hline
\end{tabular}


Table 2 Comparisons of blood pressure in non-disabled and disabled singleton cases and their matched controls and disabled singleton cases attending special schools (who have no controls)

\begin{tabular}{|c|c|c|c|c|c|c|c|}
\hline $\begin{array}{l}\text { Blood } \\
\text { pressure }\end{array}$ & $\begin{array}{l}\text { Non-disabled } \\
\text { singleton cases } \\
(n=128)\end{array}$ & $\begin{array}{l}\text { Matched controls } \\
(n=128)\end{array}$ & $\begin{array}{l}\text { Mean of differences } \\
\text { between cases and controls } \\
(95 \% \text { CI })\end{array}$ & $\begin{array}{l}\text { Disabled singleton } \\
\text { cases }(n=11)\end{array}$ & $\begin{array}{l}\text { Matched controls } \\
(n=11)\end{array}$ & $\begin{array}{l}\text { Mean of differences } \\
\text { between cases and controls } \\
(95 \% \text { CI })\end{array}$ & $\begin{array}{l}\text { Disabled cases } \\
\text { with no controls } \\
(n=23)\end{array}$ \\
\hline Systolic & $114.7(\mathrm{SD} \mathrm{12.8)}$ & 111.5 (SD 10.6) & $\begin{array}{l}3.2(0.4 \text { to } 6.0) \\
\mathrm{p}<0.05\end{array}$ & $112.1(\mathrm{SD} 14.9)$ & $111.0(\mathrm{SD} 7.8)$ & $\begin{array}{l}1.1(-9.3 \text { to } 8.8) \text { not } \\
\text { significant }\end{array}$ & $110.0(\mathrm{SD} 12.9)$ \\
\hline Diastolic & $59.4(\mathrm{SD} 8.2)$ & $58.3(\mathrm{SD} 7.5)$ & $\begin{array}{l}1.1(-0.7 \text { to }+2.9) \\
\text { not significant }\end{array}$ & $59.0(\mathrm{SD} 7.4)$ & $58.5(\mathrm{SD} 7.1)$ & $\begin{array}{l}0.5(-4.9 \text { to } 6.9) \text { not } \\
\text { significant }\end{array}$ & $62.0(\mathrm{SD} 11.8)$ \\
\hline
\end{tabular}

age of the controls were not obtained, but the mean and range of birthweights indicate that most must have been term infants.

\section{ANTHROPOMETRIC MEASURES}

There were highly significant differences between both non-disabled and disabled cases and their matched controls in height, weight, and head circumference, with the cases being smaller for all variables. Cases also had a lower body mass index than controls but the difference was not significant (table 1).

A comparison of 128 non-disabled cases with all 34 disabled cases showed that the latter were smaller for all anthropometric indices; there was a $6.4 \mathrm{~cm}$ difference in height $(\mathrm{p}<0.001)$, a $1.1 \mathrm{~cm}$ difference in head circumference $(p=0.001)$, and a $5.0 \mathrm{~kg}$ difference in weight $(p<0.01)$. The 0.34 unit difference in body mass index did not quite attain the conventional level of significance $(p<0.07)$.

Within the group of disabled children, those attending special schools for whom there were no controls, were even shorter and lighter than those who attended normal schools, though the differences were not significant (table 1).

SMOKING HABIT

Among the non-disabled group, 20/127 (16\%) of the cases and 5/127 (4\%) of the controls were current smokers. The difference was significant (McNemar's exact test; $\mathrm{p}<0.01$ ). Similarly, among the mothers, current smoking status (ever vs never smoked) or smoking status at the time of the pregnancy was significantly different in cases and controls. Among the cases, $87 / 126(69 \%)$ of mothers compared with $59 / 126(47 \%)$ control mothers have ever smoked (McNemar's $\left.\chi^{2}, 1 \mathrm{df}=6.7 ; \mathrm{p}<0.01\right)$.

BLOOD PRESSURE

The systolic blood pressure was significantly higher in the non-disabled cases than controls; the mean of the differences in each case control pair was $3.2 \mathrm{~mm} \mathrm{Hg}, \mathrm{p}<0.05$. The diastolic pressure was also higher in cases than controls but the difference was not significant. Systolic and diastolic blood pressures were higher in disabled cases than their controls, but with only 11 disabled case control pairs, the differences were not significant. Comparison of nondisabled with the disabled cases showed no significant differences in either systolic or diastolic blood pressure (table 2).

There was a significant positive correlation between systolic blood pressure and height, weight and body mass index, for cases and controls. The regression coefficients-the gradient of the association, of systolic pressure with height, weight and body mass indexwere greater for cases than for controls, although the differences in gradients were not significant (table 3).

In contrast to the systolic pressure, there was no association between diastolic pressure and height in cases or controls. Weight and body mass index were significantly associated with diastolic pressure but the association was weaker than that for systolic pressure. The regression coefficients for the cases were greater than those for the controls, but the differences were not significant (table 3 ).

In a multiple regression of systolic and diastolic blood pressures on the anthropometric variables and mother and child's smoking status, no significant associations were observed.

Because blood pressure correlated positively with the anthropometric variables, the systolic and diastolic pressures were adjusted for height, weight, and body mass index separately and a paired case control comparison of blood pressure was made. Adjusting for each anthropometric variable increased the case control differences in systolic pressure and these differences remained highly significant. The case control differences in diastolic pressure also were marginally increased but remained non-significant (table 4).

Table 3 Correlation of blood pressure with height, weight, body mass index and head circumference

\begin{tabular}{|c|c|c|c|c|}
\hline & \multicolumn{2}{|c|}{ Non-disabled cases $(n=128)$} & \multicolumn{2}{|c|}{ Controls $(n=128)$} \\
\hline & $\begin{array}{l}\text { Correlation } \\
\text { coefficient }\end{array}$ & $\begin{array}{l}\text { Regression coefficient } \beta \\
(S E \text { of } \beta)\end{array}$ & $\begin{array}{l}\text { Correlation } \\
\text { coefficient }\end{array}$ & Regression coefficient $\beta$ (SE of $\beta$ ) \\
\hline \multicolumn{5}{|l|}{ Height } \\
\hline Systolic BP & 0.30 & $0.49(0.14) \mathrm{p}=0.001$ & 0.17 & $0.23(0.12) p=0.06$ \\
\hline Diastolic BP & 0.01 & $0.01(0.09)$ not significant & 0.07 & $-0.06(0.09)$ not significant \\
\hline \multicolumn{5}{|l|}{ Weight } \\
\hline Systolic BP & 0.50 & $0.59(0.09) \mathrm{p}<0.0001$ & 0.36 & $0.37(0.08) p<0.0001$ \\
\hline Diastolic BP & 0.20 & $0.15(0.07) \mathrm{p}=0.02$ & 0.17 & $0.12(0.06) \mathrm{p}=0.06$ \\
\hline \multicolumn{5}{|l|}{ Body mass index } \\
\hline Systolic BP & 0.43 & $16.6(3.1) \mathrm{p}<0.0001$ & 0.35 & $11.3(2.7) \mathrm{p}=0.0001$ \\
\hline Diastolic BP & 0.25 & $6.2(2.1) \mathrm{p}=0.004$ & 0.26 & $6.0(2.0) \mathrm{p}=0.003$ \\
\hline \multicolumn{5}{|c|}{ Head circumference } \\
\hline Systolic BP & 0.22 & $1.43(0.57) \mathrm{p}<0.05$ & 0.18 & $1.10(0.58) \mathrm{p}=0.06$ \\
\hline Diastolic BP & 0.03 & $0.14(0.38)$ not significant & 0.05 & $0.24(0.42)$ not significant \\
\hline
\end{tabular}


Table 4 Case control differences in adjusted systolic and diastolic blood pressure (128 unimpaired case-control pairs)

\begin{tabular}{lll}
\hline & \multicolumn{2}{l}{ Means of differences between cases and controls } \\
\cline { 2 - 3 } & Systolic blood pressure (95\% CI) & Diastolic blood pressure (95\% CI) \\
\hline Adjusted for height & $4.4(1.8$ to 7.0$) ; \mathrm{p}=0.001$ & $0.9(-0.9$ to +2.7$) ;$ not significant \\
Adjusted for weight & $5.1(2.7$ to 7.5$) ; \mathrm{p}<0.001$ & $1.6(-0.2$ to +3.4$) ;$ not significant \\
Adjusted for body mass index & $4.2(1.6$ to 6.8$) ; \mathrm{p}=0.002$ & $1.5(-0.3$ to +3.3$)$; not significant \\
\hline
\end{tabular}

\section{Discussion}

The advantages of this study are that it reports a total population of low birthweight children from a geographically defined area and that a high follow up rate of $95 \%$ was achieved so that any non-response bias will be small. However, a possible bias could result from the high neonatal mortality among the cases, and the infants who died were probably among the most preterm and most growth retarded. This being so, the case control differences reported here would err towards being an underestimate of the true differences.

Unlike other studies that have been quoted which examine cohorts of children across the whole birthweight frequency distribution, the study we report here is unique in that it focuses on cases which were from one extreme of the birthweight frequency distribution with a birthweight cutoff point of $1500 \mathrm{~g}$. This will enhance differences between cases and controls that are attributable to birthweight. Furthermore, because the cutoff was determined by birthweight and not gestational age, the cases will have a disproportionate number of intrauterine growth retarded infants included. Therefore, any association between fetal growth retardation and blood pressure will be accentuated in the comparison between cases and controls.

Infants who were of low birthweight continued to show significant differences in all the important parameters of growth at the time of adolescence compared with their normal birthweight controls. The association between increased weight and body mass and hypertension in adults is well recognised and, therefore, the difference in growth shown by the cohort of low birthweight adolescents has potentially important implications for subsequent levels of blood pressure, particularly if the growth trajectories are maintained into adulthood, leading to more pronounced differences in height, weight, and body mass index.

At 15 years of age the important difference between the low birthweight cases and their age and sex matched controls was in their systolic blood pressures; their diastolic blood pressures were not significantly different. As the cases were smaller than their controls in all the anthropometric indices, adjusting for these indices only served to increase the case control blood pressure differences. The difference in systolic blood pressure became more pronounced but the diastolic blood pressure difference remained non-significant. Birthweight is, therefore, independently associated with adolescent systolic, but not diastolic, blood pressure. This confirms the report of a cross sectional study of 8-11 year old children in which it was found that birthweight was inversely related to blood pressure after adjustment for current body size. ${ }^{25}$

A difference of $4-5 \mathrm{~mm} \mathrm{Hg}$ in systolic pressure between cases and controls shows how much the frequency distribution curve for systolic pressure is shifted to the right in the low birthweight cases compared with the controls. In populations this is a major difference. As systolic rather than diastolic blood pressure is the important determinant of cardiovascular disease risk and curtailment of life, ${ }^{26} 27$ the observation that birthweight and intrauterine growth retardation primarily are associated with systolic blood pressure differences has important implications for subsequent ill health and mortality.

The regression coefficients - the gradients of the increase in blood pressure with height, weight and body mass index-were greater, though not significantly so, for the cases than the controls. Even though there was a failure to achieve significance, nevertheless, the differences could be real and are likely to persist through adolescence into adult life. It is also likely that the growth trajectories are maintained and the differences in the anthropometric indices will be further widened in adult life. If so, a multiplicative effect between gradient of the rise in blood pressure and the increase in height, weight, and body mass index will mean that adult differences in blood pressure attributable to birthweight will be even more pronounced than in adolescence.

The results support the hypothesis that birthweight and intrauterine growth retardation are positively associated with adolescent anthropometric indices and inversely associated with blood pressure after adjustment has been made for known confounding variables. However, the effects of social and economic factors acting postnatally and in early childhood cannot be discounted. Although matching cases and controls for school attenders, effectively matched for a variety of social and economic variables to the extent that no significant differences between cases and controls were found, nevertheless, the marginal differences observed all favoured the controls. ${ }^{22}$ Also, a higher proportion of the low birthweight children and their mothers are smokers compared with the controls. It is plausible that adverse social and economic influences initiate their cardiovascular effects during fetal development and are compounded during childhood, adolescence, and adulthood. The difficulty is to determine the proportional contribution during the different phases of development.

We thank the young participants, their parents, and school staff for their excellent cooperation throughout the study, the British Heart Foundation for funding the study, and Seca Ltd for donating the Seca Patient Scales and the Leicester Height donating 
1 Barker DJP, Osmond C. Infant mortality, childhood nutrition, and ischaemic heart disease in England and nutrition, and ischaemic heart
Wales. Lancet 1986;: 1077-81

2 Barker DJP, Osmond C, Law CM. The intrauterine and early postnatal origins of cardiovascular disease and chronic bronchitis. F Epidemiol Community Health 1989;43:237-40.

3 Greenland S, Robins J. Ecological studies - Biases, misconceptions and counter-examples. Am $\mathcal{F}$ Epidemiol 1994;139:747-71.

4 Whincup PH, Cook DG, Shaper AG. Early influences on blood pressure: a study of children aged 5-7 years. $B M \mathcal{F}$ 1989;299:587-91

5 Law CM, Barker DJP, Bull AR, Osmond C. Maternal and fetal influences on blood pressure. Arch Dis Child 1991;66:1291-5.

6 Whincup PH, Cook DG, Papacosta O. Do maternal and intrauterine factors influence blood pressure in childhood. Arch Dis Child 1992;67:1423-9.

7 Whincup PH, Cook DG, Papacosta O, Walker M. Birthweight and blood pressure: cross sectional and longiBirthweight and blood pressure: cross sectional and longi-
tudinal relations in childhood. $B M \mathcal{F} 1995 ; 311: 773-6$.

tudinal relations in childhood. $B M \mathcal{F} 1995 ; 311: 773-6$.
8 Donker GeA, Labarthe DR, Harrist RB, Selwyn BJ, Wattigney W, Berenson GS. Low birth weight and blood pressure at age 7-11 years in a biracial sample. Am f Epidemiol 1997; 145:387-97.

9 Gennser G, Rymark P, Isberg PE. Low birth weight and risk of high blood pressure in adulthood. BMF 1988;296:1498500 .

10 Barker DJP, Osmond C, Golding J, Kuh D, Wadsworth MEJ. Growth in utero, blood pressure in childhood and adult life, and mortality from cardiovascular disease. $B M \mathcal{F}$ 1989;298:564-7.

11 Holland FJ, Stark O, Ades AE, Peckham CS. Birth weight and body mass index in childhood, adolescence and adulthood as predictors of blood pressure at age 36. F Epidemiol Community Health 1993;47:432-5.

12 Barker DJP, Bull AR, Osmond C, Simmonds SJ. Fetal and placental size and risk of hypertension in adult life. $B M \mathcal{Y}$ placental size and

13 Law CM, de Swiet M, Osmond C, et al. Initiation of hypertension in utero and its amplification throughout life. $B M \mathcal{Y}$ 1993:306:24-7.

14 Law CM, Shiell AW. Is blood pressure inversely related to birthweight? The strength of evidence from a systematic review of the literature. $\mathcal{F}$ Hypertension 1996;14:935-41.
15 Hales CN, Barker DJP, Clark PMS, et al. Fetal and infant growth and impaired glucose tolerance at age $64 . B M 7$ 1991;303:1019-22.

16 MacIntyre S, Watt G, West P, Ecob R. Correlates of blood pressure in the west of Scotland. I Epidemiol Community Health 1991;45:1291-5.

17 Seidman DS, Laor A, Gale R, Stevenson DK, Mashiack S, Danon Yl. Birthweight, current body weight, and blood pressure in late adolescence. BMF 1991;302:1235-6.

18 Mattes JWA, Lewis PA, Davies DP, Bethel JA. Relation between birthweight at term and systolic blood pressure in adolescence. $B M \mathcal{F}$ 1993;306:24-7.

19 Williams S, St George IM, Silva PA. Intra-uterine growth retardation and blood pressure at age seven and eighteen. f Clin Epidemiol 1992;45:1257-73.

20 Laor A, Stevenson DK, Shemer J, Gale R, Seidman DS. Size at birth, maternal nutritional status in pregnancy, and blood pressure at age 17: a population based analysis. $B M \mathcal{F}$ 1997;315:449-52

21 Powell TG, Pharoah POD, Cooke RWI. Survival and morbidity in a geographically defined population of low birthweight infants. Lancet 1986;i:539-43.

22 Pharoah POD, Stevenson CJ, Cooke RWI, Stevenson RC. Clinical and subclinical deficits at 8 years in a geographically defined cohort of low birthweight infants. Arch Dis Child 1994;70:F264-F70.

23 Pharoah POD, Stevenson CJ, Cooke RWI, Stevenson RC. Prevalence of behaviour disorders in low birthweight infants. Arch Dis Child 1994;70:F271-F4.

24 Whincup PH, Cook DG, Shaper AG, Macfarlane DJ, Walker M. Blood pressure in British children: associations with adult blood pressure and cardiovascular mortality. Lancet 1988;ii:890-3.

25 Taylor SJC, Whincup PH, Cook DG, Papacosta O, Walker M. Size at birth and blood pressure: cross sectional study in 8-11 year old children. BMf 1997;314:475-80.

26 Stamler J, Stamler R, Neaton JD. Blood pressure, systolic and diastolic, and cardiovascular risks. Arch Intern Med 1993;153:598-615.

27 Rutan GH, McDonald RH, Kuller LH. A historical perspective of elevated systolic vs diastolic blood pressure from an epidemiological and clinical trial viewpoint. $f$ Clin Epidemiol 1989;42:663-73. 